\title{
Hazır Beton Firmalarının Üretim Stratejilerinin Çevre Bilinci ve Sürdürülebilir Kalkınma Bakış Açısıyla Değerlendirilmesi
}

\author{
Hamdi Tekin* \\ 1* İstanbul Arel Üniversitesi, Mühendislik-Mimarlık Fakültesi, İnşaat Mühendisliği Bölümü, İstanbul, Türkiye, (ORCID: 0000-0003-1480-9452), \\ hamditekin@arel.edu.tr \\ (Uluslararası Araştırma-Geliştirme ve Tasarım Konferansı - 15-18 Aralık 2021)
}

(DOI: 10.31590/ejosat.1045969)

\begin{abstract}
ATIF/REFERENCE: Tekin H. (2021). Hazır Beton Firmalarının Üretim Stratejilerinin Çevre Bilinci ve Sürdürülebilir Kalkınma Bakış Açısılla Değerlendirilmesi. European Journal of Science and Technology, (32), 843-849

$\ddot{O} z$

Artan çevre kirliliği ve küresel ısınma sonucunda iklim değişliği günümüzün en önemli sorunlarından biri haline gelmiştir. Türkiye'deki yapı stoğunun çok büyük bir kısmı betonarme yapılardan oluşmaktadır. Betonarme yapılar diğer yapım türleriyle karşıllaştırıldığında çevreye ciddi zarar vermekte, aynı zamanda da enerji tüketimini arttırmaktadır. İstanbul gibi inşaat ve bina yoğunluğunun çok fazla olduğu metropolitan şehirlerde çevre kirliliği daha da fazla hissedilmektedir. Bu sorunun çözümünde iki seçenek söz konusudur. Bunlar betonarme yapılar yerine ahşap, çelik gibi daha sürdürülebilir yapılar tercih etmek ya da betonarme yapıları daha sürdürülebilir stratejilerle imal etmektir. Gerek yeterli düzeyde kalifiye eleman bulunmaması sorunu gerekse de hammadde ve lojistik maliyetlerinin fazla oluşu, diğer yapı türlerinin yaygın kullanımını sınırlamaktadır. Bu nedenle kısa vadade, betonarme yapım imalatlarını çevreye en az zarar verecek şekilde üretmek sürdürülebilir kalkınma açısından önem arz etmektedir. Bu çalışma, hazır beton firmalarının üretim stratejilerinin çevre bilinci ve sürdürülebilir kalkınma bakış açısıyla değerlendirilmeyi amaçlamıştır. Çalışma kapsamında farklı şehirlerde bulunan hazır beton firma yetkililerine anketler uygulanmıştır. Sonuç olarak hazır beton firmalarının sürdürülebilir imalat stratejilerini yeterince benimsemedikleri gözlemlenmiştir. Gerekli farkındalığın oluşması ve AR-GE çalışmalarının gelişmesi için eğitimlerin verilmesi, teşvik ve yaptırımların uygulanması, sürdürülebilir ürünlerle ilgili talebin oluşturulması için aksiyonlar alınması gerekmektedir.
\end{abstract}

Anahtar Kelimeler: Sürdürülebilir beton, Hazır beton, Sürdürülebilir kalkınma, Çevre bilinci

\section{Evaluation of the manufacturing strategies of ready-mixed concrete companies from the perspective of environmental awareness and sustainable development}

\begin{abstract}
Climate change has become one of the most important problems of our time as a result of increasing environmental pollution and the global warming. A large part of the building stock in Turkey consists of reinforced concrete structures. Compared to other construction types, reinforced concrete structures cause serious damage to the environment and also increase energy consumption. Environmental pollution is felt even more in metropolitan cities such as Istanbul, where the construction and building density is very high. There are two options for solving this problem. These are to prefer more sustainable structures such as wood and steel instead of reinforced concrete structures or to manufacture reinforced concrete structures with more sustainable strategies. Both the problem of availability of qualified personnel and the high costs of raw materials and logistics limit widespread use of other building types. Therefore, in the short term, it is important for sustainable development to construct reinforced concrete structures in a way that they cause the least damage to the environment. This study aimed to evaluate the production strategies of ready-mixed concrete companies from the perspective of environmental awareness and sustainable development. Within the scope of the study, questionnaires were applied to ready-mixed concrete company officials in different cities. As a result, it has been observed that ready-mixed concrete companies do not adopt sustainable manufacturing strategies at desired level. In order to raise awareness and develop R\&D studies, trainings should be given, incentives and sanctions should be applied and actions should be taken to create demand for sustainable products.
\end{abstract}

Keywords: Sustainable concretei Ready-mixed concrete, Sustainable development, Environmental awareness

\footnotetext{
* Sorumlu Yazar: hamditekin@arel.edu.tr
} 


\section{Giriş}

Artan nüfus, teknolojik gelişmelerin hızla ilerlemesi ve ülkelerin ekonomik kalkınma süreçleri enerjiye olan talebi orantılı şekilde arttırmaktadır (Güner ve diğ., 2017). Enerji alanında arz güvenliğinin sağlanabilmesi için enerjinin tasarruflu kullanılması ve sahip olunan fosil yakıt kaynaklarının değerlendirmesi dişında, yenilenebilir enerji kaynaklarından en etkin şekilde yararlanılması gerekmektedir (Doğan ve Yılankıran, 2015). Buna ek olarak sürdürülebilir malzeme ve çevre kirliliğine en az katkısı olacak süreçler tasarlamak sürdürülebilir kalkınmaya büyük katkı sağlayacaktır. Sürdürülebilirlik, gezegenimizin refahı, toplulumuzun gelişmesi ve insanlık için önemlidir(Naik, 2008).Sürdürülebilir yap1 malzemeleri, yaşam döngüleri boyunca asgari ölçüde enerji harcayan, hammaddelerinin elde edilmesi, işlenmesi, kullanımı, bakım-onarım ve atık oluşumları sırasında çevreye ve insan sağlığına zarar vermeyen malzemelerdir (Orhon, 2012).Nüfus artışınınn ve eskiyen binaların tekrar yapılması ihtiyacının bir sonucu olarak daha çok konut, yol, köprü, vb. yapılar inşa edilecektir (Yılmaz ve diğ., 2013). Betonarme yapıları üretmek için gereken çelik ve beton enerji sarfiyatı çok yüksek olan malzamelerdir. Beton, su dişında kütlece dünyada en çok tüketilen malzemedir (Monteiro, 2017).Türkiye'de mevcut inşaatların tamamına yakınında hazır beton kullanılmaktadır. Betonun çevresel etkisini, enerji ve $\mathrm{CO} 2$ yoğunluğunu en aza indirmek için beton karışım tasarımında yaşam döngüsü ve sürdürülebilir mühendislik yaklaşımlarını kullanmak mantıklı olacaktır (Berndt, 2009). Özellikle betonun içeriğinde bulunan çimentoyu üretmek için yoğun bir enerji tüketimi gerekmekte, bu üretim sürecinde çevreye zararlı emisyonlar söz konusu olup açığa çıkan karbondioksit ve sera etkisi yapıcı gazlar çevreye salınmaktadır (Toker, 2013; Özcan ve Güngör, 2019). Karbondioksit emisyonlarının \%8'inin beton üretimi kaynaklı olması, betonun çok dikkatli bir şekilde kullanımının önemini arttırmıştır (Arıoğlu ve diğ., 2004).Bu nedenle, çimento ve beton endüstrilerinde yer alan profesyoneller, endüstrilerin gelecekleri ve çevremizin sağlığını korumak için kalıcı yenilikler üretme sorumluluğuna sahiptir (Naik, 2008).

Geri dönüştürülmüş malzemelerin beton üretiminde kullanılması, çevresel ayak izini azaltmak için tercih edilen bir yaklaşım haline gelmiştir (Bostanc1, 2019). Bu nedenle, betonun üretim sürecinde çevreye etkisini en aza indirmek amacıyla birçok çalışma yapılmıştır. Orhon (2012) çalışmasında, yapım süreçlerinde betonun sürdürülebilirliğini arttırmak üzere kullanılabilecek temel yaklaşımlara değinerek, betonun gömülü karbondioksit değerlerini azaltmayı hedef alan bir çalışma gerçekleştirmiştir. Yılmaz ve diğ. (2013) kentsel dönüşüm projelerinde yıkılacak binalardan elde edilecek molozların agrega olarak kullanılmasinın, suyun aritılarak tekrar betonda değerlendirilmesinin, diğer sektörlerin atıkları, yan ürünleri olan uçucu kül, öğütülmüş granüle yüksek fırın cürufu, silis dumanının beton üretiminde kullanılmasının önemini vurgulamıştır. Demirel ve Şimşek (2015) çalışmasında yaşı 7 gün ve sınıfı C30 olan beton atıklarından elde edilen iri ve ince agreganın geri dönüşüm agregası olarak betonda kullanım olanaklarını araştırmış, bu agregaların beton üretiminde kullanabileceği sonucuna varmıştır. Sancak ve Şamandar (2015), atık maddelerin kendinden yerleşen beton üretiminde kullanımının sürdürülebilirlik boyutunda potansiyel katkısı üzerinde durmuştur. Günümüzde insan temelli çevre sorunlarından birisi de düzenli ve düzensiz depolama alanlarındaki atıklardan kaynaklanmaktadır (Özel, 2018). İnşaat atıklarının yeniden kullanımı, Yaşam Döngüsü Değerlendirmesi ve inşaat kaynaklarının etkin bir şekilde geri dönüştürülmesi açısından son derece önemlidir (Dosho, 2007). Bozkurt ve Yazıcıoğlu (2010), sürdürülebilir taşıyıcı hafif beton tasarımı ve mekanik özellikler üzerine yaptıkları araştırma sonucunda Elazı̆̆ yöresinden elde edilen pomzanın taşıyıcı hafif beton üretiminde sürdürülebilir bir malzeme olarak kullanılabileceği görüşünü ortaya koymuşlardır. Altınışık (2014), atık betonların geri kazanılmış agrega olarak yeni beton üretiminde kullanımını araştırmıştır. Assi ve diğ. (2018), araştırmasında maliyet açısından rekabetçi, çevre dostu bir jeopolimer beton karışımının geliştirilmesine odaklanmıştır. Jonkers ve diğ. (2010), bakterilerin betonda kendi kendini iyileştirme ajanı olarak hareket etme potansiyelini, yani oluşan çatlakları onarma yeteneklerini araştırmıştır. Coşkun ve diğ. (2017) hazır beton tesislerinde biriken atık suların beton üretiminde kullanılabilirliği ve üretilen betona etkisini incelemiş, sonuç olarak geri dönüşüm suyu ve kuyu suyu ile hazırlanan beton karışımlarında taze betonun sıcaklık, birim ağırlık, slump ve hava miktarlarında önemli bir farklılık görülmediğini ortaya koymuşlardır.Göksu ve diğ. (2018) çalışmasında belirli oranda beton karışımına ikame edilen geri dönüşümlü agreganın betonun mekanik özelliklerine etkisi incelemiştir.

Tüm bu çalışmaların yaygın kullanıma dönüşebilmesi ancak sürdürülebilir üretim anlayışının yaygınlaşması sonucunda gerçekleşebilir. Bu nedenle, hazır beton firmalarının üretim bakış açıları gelecekteki betonun ne derece sürdürülebilir olup olmayacağını belirleyecektir. Bu doğrultuda çalışma, hazır beton firmalarının üretim stratejilerinin çevre bilinci ve sürdürülebilir kalkınma bakış açısıyla değerlendirmeyi amaçlamıştır..

\section{Materyal ve Metot}

$\mathrm{Bu}$ çalışmada nicel araştırma yöntemi tercih edilmiştir. Çalışma kapsamında farklı şehirlerde çalışan 74 farklı hazır beton firması yetkilisine anketler uygulanmıştır. Anketteki sorular Likert tipinden oluşan toplam 27 sorudan oluşmaktadır. Sorular beş kategoride değerlendirilmiştir. İlk kategoride hazır beton firma yetkililerinin çevre bilinci ve sürdülebilirlik konusundaki farkındalıkları, ikinci kategoride sürüdülebilirlik konusunda genel stratejilere bakış açıları, üçüncü kategoride imalat süreçlerinde, dördüncü kategoride ise AR-GE süreçlerinde sürdürülebilir çözümlerin ne derece yer aldığ 1 , beşinci kategoride ise sürdürülebilirlik konusunda gelecekteki beklentiler yer almaktadır. Tüm veriler toplandıktan sonra veriler betimsel istatistik yöntemleri (frekans ve yüzde hesabı) ile analiz edilmiştir. 
Tablo 1. Çevre bilinci ve sürdülebilirlik konusundaki farkındalıkları soruları

\begin{tabular}{|c|c|c|c|c|c|c|c|c|c|c|}
\hline \multirow{3}{*}{$\begin{array}{l}\text { 1. Kategori: Çevre bilinci ve } \\
\text { sürdülebilirlik konusundaki } \\
\text { farkındalıkları soruları }\end{array}$} & \multicolumn{10}{|c|}{$\mathrm{N}=74$} \\
\hline & \multicolumn{2}{|c|}{ Hiç yok (1) } & \multicolumn{2}{|c|}{$\mathrm{Az}(2)$} & \multicolumn{2}{|r|}{ Orta (3) } & \multicolumn{2}{|c|}{ Fazla (4) } & \multicolumn{2}{|c|}{$\begin{array}{l}\text { Çok Fazla } \\
\qquad(5)\end{array}$} \\
\hline & $\mathrm{f}$ & $\%$ & $\mathrm{f}$ & $\%$ & $\mathrm{f}$ & $\%$ & $\mathrm{f}$ & $\%$ & $\mathrm{f}$ & $\%$ \\
\hline $\begin{array}{l}\text { Kendini yenileyen beton hakkında } \\
\text { bilginiz var mi? }\end{array}$ & 19 & $25,68 \%$ & 22 & $29,73 \%$ & 11 & $14,86 \%$ & 12 & $16,22 \%$ & 10 & $13,51 \%$ \\
\hline $\begin{array}{l}\text { Sürdürülebilir beton vb ürünler } \\
\text { hakkında bilginiz var mı? }\end{array}$ & 21 & $28,38 \%$ & 21 & $28,38 \%$ & 13 & $17,57 \%$ & 8 & $10,81 \%$ & 11 & $14,86 \%$ \\
\hline $\begin{array}{l}\text { Beton ve çimento üretimi yaparken } \\
\text { daha az enerji tüketmek sizce } \\
\text { mümkün müdür? }\end{array}$ & 8 & $10,81 \%$ & 11 & $14,86 \%$ & 15 & $20,27 \%$ & 27 & $36,49 \%$ & 13 & $17,57 \%$ \\
\hline $\begin{array}{l}\text { Sürdürülebilir ürün } \\
\text { pahalı olduğunulatının } \\
\text { musunuz? }\end{array}$ & 5 & $6,76 \%$ & 12 & $16,22 \%$ & 6 & $8,11 \%$ & 31 & $41,89 \%$ & 20 & $27,03 \%$ \\
\hline $\begin{array}{l}\text { Klasik çimento ve beton } \\
\text { kullanımının çevreye ciddi bir zarar } \\
\text { verdiğini düşünüyor musunuz? }\end{array}$ & 7 & $9,46 \%$ & 16 & $21,62 \%$ & 23 & $31,08 \%$ & 18 & $24,32 \%$ & 10 & $13,51 \%$ \\
\hline 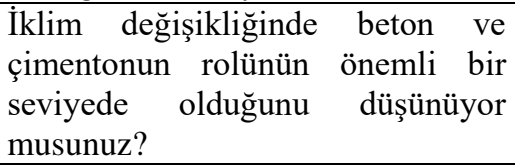 & 6 & $8,11 \%$ & 22 & $29,73 \%$ & 17 & $22,97 \%$ & 20 & $27,03 \%$ & 9 & $12,16 \%$ \\
\hline
\end{tabular}

Tablo 2. Sürdürülebilirlik Konusunda Genel Stratejilerin Değerlendirilmesine Yönelik Soruların Analizi

\begin{tabular}{|c|c|c|c|c|c|c|c|c|c|c|}
\hline \multirow{3}{*}{$\begin{array}{l}\text { 2. Kategori: Sürdürülebilirlik } \\
\text { konusunda genel stratejilerin } \\
\text { değerlendirilmesine yönelik } \\
\text { sorular }\end{array}$} & \multicolumn{10}{|c|}{$\mathrm{N}=74$} \\
\hline & \multicolumn{2}{|c|}{ Hiç yok (1) } & \multicolumn{2}{|c|}{$\mathrm{Az}(2)$} & \multicolumn{2}{|c|}{ Orta (3) } & \multicolumn{2}{|c|}{ Fazla (4) } & \multicolumn{2}{|c|}{ Çok Fazla (5) } \\
\hline & $\mathrm{f}$ & $\%$ & $\mathrm{f}$ & $\%$ & $\mathrm{f}$ & $\%$ & $\mathrm{f}$ & $\%$ & $\mathrm{f}$ & $\%$ \\
\hline $\begin{array}{l}\text { Kentsel dönüşüm projelerindeki } \\
\text { y1kıntılar sizce yeteri kadar geri } \\
\text { dönüşüm malzemesi olarak } \\
\text { kullanıyor mu? }\end{array}$ & 30 & $40,54 \%$ & 25 & $33,78 \%$ & 14 & $18,92 \%$ & 4 & $5,41 \%$ & 1 & $1,35 \%$ \\
\hline $\begin{array}{l}\text { Yenilikçi, sürdürülebilir ve çevre } \\
\text { dostu ürün elde etmek için yeteri } \\
\text { kadar teşvik oluğunu düşünüyor } \\
\text { musunuz? }\end{array}$ & 34 & $45,95 \%$ & 18 & $24,32 \%$ & 14 & $18,92 \%$ & 8 & $10,81 \%$ & 0 & $0,00 \%$ \\
\hline 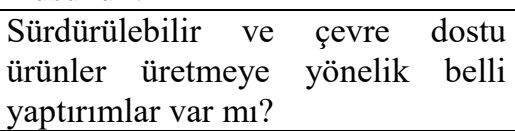 & 32 & $43,24 \%$ & 22 & $29,73 \%$ & 12 & $16,22 \%$ & 8 & $10,81 \%$ & 0 & $0,00 \%$ \\
\hline $\begin{array}{l}\text { Varsa, bu yaptırımların yeterli } \\
\text { olduğunu düşünüyor musunuz? }\end{array}$ & 46 & $62,16 \%$ & 15 & $20,27 \%$ & 10 & $13,51 \%$ & 3 & $4,05 \%$ & 0 & $0,00 \%$ \\
\hline $\begin{array}{l}\text { Çimento ve beton üreticilerinin } \\
\text { çevreye yeteri kadar önem verdiğini } \\
\text { düşünüyor musunuz? }\end{array}$ & 15 & $20,27 \%$ & 21 & $28,38 \%$ & 22 & $29,73 \%$ & 13 & $17,57 \%$ & 5 & $6,76 \%$ \\
\hline
\end{tabular}




\begin{tabular}{|c|c|c|c|c|c|c|c|c|c|c|}
\hline \multirow{3}{*}{$\begin{array}{l}\text { 3. Kategori: İmalatlarda } \\
\text { sürdürülebilir çözümlerin ne } \\
\text { derece yer aldığına yönelik } \\
\text { sorular }\end{array}$} & \multicolumn{10}{|c|}{$\mathrm{N}=74$} \\
\hline & \multicolumn{2}{|c|}{ Hiç yok (1) } & \multicolumn{2}{|c|}{$\mathrm{Az}(2)$} & \multicolumn{2}{|c|}{ Orta (3) } & \multicolumn{2}{|c|}{ Fazla (4) } & \multicolumn{2}{|c|}{ Çok Fazla (5) } \\
\hline & $f$ & $\%$ & $\mathrm{f}$ & $\%$ & $\mathrm{f}$ & $\%$ & $f$ & $\%$ & $\mathrm{f}$ & $\%$ \\
\hline $\begin{array}{l}\text { Sürdürülebilir ve çevre } \\
\text { ürünler imal ediyor musunuz? }\end{array}$ & 17 & $22,97 \%$ & 14 & $18,92 \%$ & 29 & $39,19 \%$ & 7 & $9,46 \%$ & 7 & $9,46 \%$ \\
\hline $\begin{array}{l}\text { İmal ettiğiniz ürünlerde daha az } \\
\text { enerji tüketen ikame maddeler } \\
\text { kullanyor musunuz? }\end{array}$ & 11 & $14,86 \%$ & 17 & $22,97 \%$ & 25 & $33,78 \%$ & 10 & $13,51 \%$ & 11 & $14,86 \%$ \\
\hline $\begin{array}{l}\text { Kurumunuz çevre konusunda hassas } \\
\mathrm{m} \text { ? }\end{array}$ & 0 & $0,00 \%$ & 3 & $4,05 \%$ & 15 & $20,27 \%$ & 26 & $35,14 \%$ & 30 & $40,54 \%$ \\
\hline $\begin{array}{l}\text { Çevre dostu, sürdürülebilir ürünler } \\
\text { imal etmek bireysel olarak sizin için } \\
\text { önemli mi? }\end{array}$ & 1 & $1,35 \%$ & 7 & $9,46 \%$ & 9 & $12,16 \%$ & 20 & $27,03 \%$ & 37 & $50,00 \%$ \\
\hline $\begin{array}{l}\text { İmal ettiğiniz ürünlerde atık } \\
\text { malzeme kullanıyor musunuz? }\end{array}$ & 16 & $21,62 \%$ & 16 & $21,62 \%$ & 14 & $18,92 \%$ & 15 & $20,27 \%$ & 13 & $17,57 \%$ \\
\hline
\end{tabular}

Tablo-4. AR-GE çalışmalarında sürdürülebilir çözümlerin ne derece yer aldı̆̆ına yönelik soruların analizi

\begin{tabular}{|c|c|c|c|c|c|c|c|c|c|c|}
\hline \multirow{3}{*}{$\begin{array}{l}\text { 4. Kategori: AR-GE } \\
\text { çalışmalarında sürüdürülebilir } \\
\text { çözümlerin ne derece yer aldığına } \\
\text { yönelik sorular }\end{array}$} & \multicolumn{10}{|c|}{$\mathrm{N}=74$} \\
\hline & \multicolumn{2}{|c|}{ Hiç yok (1) } & \multicolumn{2}{|c|}{$\mathrm{Az}(2)$} & \multicolumn{2}{|c|}{ Orta (3) } & \multicolumn{2}{|c|}{ Fazla (4) } & \multicolumn{2}{|c|}{ Çok Fazla (5) } \\
\hline & $\mathrm{f}$ & $\%$ & $\mathrm{f}$ & $\%$ & $\mathrm{f}$ & $\%$ & $\mathrm{f}$ & $\%$ & $f$ & $\%$ \\
\hline $\begin{array}{l}\text { Kurumunuzda çevre ve enerji } \\
\text { bakımından daha verimli ürünler } \\
\text { elde etme konusunda } \\
\text { çalışmaları yapılıyor mu? }\end{array}$ & 12 & $16,22 \%$ & 22 & $29,73 \%$ & 12 & $16,22 \%$ & 12 & $16,22 \%$ & 16 & $21,62 \%$ \\
\hline $\begin{array}{l}\text { Bu tür AR-GE çalışmaları için } \\
\text { yeterli miktarda bütçe ayrılıyor mu? }\end{array}$ & 20 & $27,03 \%$ & 25 & $33,78 \%$ & 14 & $18,92 \%$ & 8 & $10,81 \%$ & 7 & $9,46 \%$ \\
\hline $\begin{array}{l}\text { Bu tür AR-GE çalışmaları için yeteri } \\
\text { kadar personel istihdam ediliyor } \\
\text { mu? }\end{array}$ & 29 & $39,19 \%$ & 18 & $24,32 \%$ & 14 & $18,92 \%$ & 8 & $10,81 \%$ & 5 & $6,76 \%$ \\
\hline $\begin{array}{l}\text { Dünyada yeni çıkan ürünlerle ilgili } \\
\text { eğitimler alıyor musunuz? }\end{array}$ & 21 & $28,38 \%$ & 17 & $22,97 \%$ & 20 & $27,03 \%$ & 9 & $12,16 \%$ & 7 & $9,46 \%$ \\
\hline $\begin{array}{l}\text { Çevre dostu, sürdürülebilir ürünler } \\
\text { imal etmek için fikir, proje vs. } \\
\text { ürettiniz mi? }\end{array}$ & 36 & $48,65 \%$ & 19 & $25,68 \%$ & 9 & $12,16 \%$ & 8 & $10,81 \%$ & 2 & $2,70 \%$ \\
\hline
\end{tabular}

Tablo 5- Sürdürülebilirlik konusunda gelecekteki beklentilere yönelik soruların analizleri

\begin{tabular}{|c|c|c|c|c|c|c|c|c|c|c|}
\hline \multirow{3}{*}{$\begin{array}{lc}\text { 5. Kategori: } & \text { Sürdürülebilirlik } \\
\text { konusunda } & \text { gelecekteki } \\
\text { beklentilere yönelik sorular }\end{array}$} & \multicolumn{10}{|c|}{$\mathrm{N}=74$} \\
\hline & \multicolumn{2}{|c|}{ Hiç yok (1) } & \multicolumn{2}{|c|}{$\mathrm{Az}(2)$} & \multicolumn{2}{|c|}{ Orta (3) } & \multicolumn{2}{|c|}{ Fazla (4) } & \multicolumn{2}{|c|}{ Çok Fazla (5) } \\
\hline & $\mathrm{f}$ & $\%$ & $\mathrm{f}$ & $\%$ & $\mathrm{f}$ & $\%$ & f & $\%$ & $\mathrm{f}$ & $\%$ \\
\hline $\begin{array}{l}\text { Betonun ömrünün uzatılması sizce } \\
\text { mümkün mü? }\end{array}$ & 1 & $1,35 \%$ & 7 & $9,46 \%$ & 20 & $27,03 \%$ & 22 & $29,73 \%$ & 24 & $32,43 \%$ \\
\hline $\begin{array}{l}\text { Betonun içine bakteri yerleştirmek } \\
\text { ve bu sayede betonun ömrünü }\end{array}$ & 14 & $18,92 \%$ & 19 & $25,68 \%$ & 25 & $33,78 \%$ & 12 & $16,22 \%$ & 4 & $5,41 \%$ \\
\hline
\end{tabular}




\begin{tabular}{l|l|l|l|l|l|l|l|l|l|l}
\hline $\begin{array}{l}\text { uzatmak sizce makul bir alternatif } \\
\text { midir? }\end{array}$ & & & & & & & & & & \\
\hline $\begin{array}{l}\text { Cimento ve beton kullanımının } \\
\text { ileride azalacağını düşünor } \\
\text { musunuz? }\end{array}$ & 15 & $20,27 \%$ & 15 & $20,27 \%$ & 24 & $32,43 \%$ & 10 & $13,51 \%$ & 10 & $13,51 \%$ \\
\hline $\begin{array}{l}\text { Çimentosuz beton sizce mümkün } \\
\text { mü? }\end{array}$ & 32 & $43,24 \%$ & 16 & $21,62 \%$ & 12 & $16,22 \%$ & 10 & $13,51 \%$ & 4 & $5,41 \%$ \\
\hline $\begin{array}{l}\text { Sürdürülebilir ve cevre dostu } \\
\text { ürünlere yönelik ciddi bir talep var } \\
\text { mı? }\end{array}$ & 32 & $43,24 \%$ & 21 & $28,38 \%$ & 12 & $16,22 \%$ & 8 & $10,81 \%$ & 1 & $1,35 \%$ \\
\hline $\begin{array}{l}10 \text { yıl içerisinde betonun pazardaki } \\
\text { yerinin gerileyeceğini düşünüyor } \\
\text { musunuz? }\end{array}$ & 11 & $14,86 \%$ & 20 & $27,03 \%$ & 25 & $33,78 \%$ & 12 & $16,22 \%$ & 6 & $8,11 \%$ \\
\hline
\end{tabular}

\section{Araştırma Sonuçları ve Tartışma}

\section{1. Çevre Bilinci ve Sürdülebilirlik Konusundaki Farkındalıklar}

Anket sonuçlarının ilk bölümünü oluşturan hazır beton firma yetkililerinin çevre bilinci ve sürdülebilirlik konusundaki farkındalıklarını irdeleyen sorulara verilen cevapların frekans ve yüzdeleri Tablo-1'de gösterilmiştir. Hazır beton firma temsilcilerinin sürdürülebilir beton/yeşil beton ve benzeri ürünler hakkındaki farkındalıklarının yeterli düzeyde olmadığı görülmektedir. Katılımcıların 21'i $(28,38 \%)$ hiç bir bilgi sahibi olmadığını, 21'i (28,38\%) az biligiye sahip olduğunu, 13'ü $(17,57 \%)$ orta düzeyde bilgi sahibi olduğunu, 8 'i $(10,81 \%)$ fazla bilgiye sahip olduğunu, 11 ' $i(14,86 \%)$ ise çok fazla bilgiye shaip olduğunu vurgulamıştır. Kendini yenileyen beton hakkındaki farkındalık düzeyi benzer oranlardadır.Katılımcıların yarısından çoğu $(55,41 \%)$ bu beton türü için ya hiç bir bilgi bilmediklerini ya da bilgi düzeylerinin az olduğunu ifade etmişlerdir. Klasik beton ve beton içeriğindeki çimento kullanımının çevreye ciddi bir zarar verip vermediği sorusuna, katılımcılardan 7'si $(9,46 \%)$ hiç yok, 16 'si (21,62\%) az, 23'ü (31,08\%) orta, 18'i (24,32\%) fazla, 10'u $(13,51 \%)$ çok fazla cevabını vermiştir. Bu oranlar katılımcıların klasik beton ve çimentonun çevreye ciddi zarar verdiği düşüncesinde olduklarını göstermektedir. Bu malzemelerin iklim değiş̧ikliğindeki rolünü ele alırsak, katılımcıların verdikleri cevapların değiş̧ikenlik gösterdiği görülmektedir. 22 katılımcı $(29,73 \%)$ az cevabını, 20 katılımc $(27,03 \%)$ ise fazla cevabını vermiştir. Katılımcıların klasik beton ve çimentonun çevreye ciddi zararı olduğunu düşünmekte fakat iklim değişikliği konusunda biraz daha nötr bir tutum sergilediği görülmektedir. Beton ve çimento üretimi yaparken daha az enerji tüketmenin mümkünatı konusunda katılımcıların yarısından çoğu $(54,06 \%)$ fazla veya çok fazla cevabını vermiş, katılımcıların üçte ikisinden çoğu $(68,92 \%)$ ise sürdürülebilir ürün imalatının pahalı olduğu cevabını vermiştir.

\subsection{Sürdülebilirlik Konusunda Genel Stratejilere Bakış Açısı}

Tablo-2'de sürdürülebilirlik konusunda genel stratejilerin değerlendirilmesine yönelik sorulara verilen cevapların analizi yer almaktadır. Katılımcıların çok büyük bir bölümü kentsel dönüşüm sonrasndaki yıkıntıların geri dönüşüm malzemesi olarak kullanılmadığını ya da yetersiz kullanıldığını ifade etmiştir. 30 katılımcı (40,54 \%) bu soruya hiç, 25 katılımcı ise $(33,78 \%)$ az cevabını vermiştir. Yenilikçi, sürdürülebilir ve çevre dostu ürün elde etmek için yeteri kadar teşvik olup olmadığı sorusuna, en çok hiç cevabı $(45,95 \%)$ verilmiştir. İkinci en çok verilen cevap ise az $(24,32 \%)$ olmuştur. Sürdürülebilir ürünler üretmeye yönelik yaptırımların olup olmadığı sorusunda da benzer bir cevap tablosu ortaya çıkmıştır. Katılımcıların 32'si $(43,24 \%)$ hiç cevabını, 22'si ise $(29,73 \%)$ ise az cevabını vermiştir. Varsa, bu yaptırımların yeterli olup olmadığı sorusuna ise katılımcıların çok büyük bir bölümü $(62,16 \%)$ hiç cevabını vermiştir. Beton ve çimento üreticilerinin çevreye yeterli önem verip vermediği sorusuna ise, 15 katılımcı (20,27\%) hiç, 21'i (28,38\%) az, 22'si ise (29,73\%) orta cevabını vermiştir. Bu da katılımcıların çoğunun sektördeki üreticilerin genel olarak çevreye yeterli düzeyde önem vermediğini düşündüklerini ortaya koymaktadır.

\section{3. İmalat Süreçlerinde Sürdürülebilir Çözümler}

Tablo-3’te imalatlarda sürdürülebilir çözümlerin ne derece yer aldığına yönelik sorulara verilen cevapların analizleri görülmektedir. 'Sürdürülebilir ve çevre dostu ürünler imal ediyor musunuz?' sorusuna 29 katılımcı orta düzeyde $(39,19 \%)$ cevabını verilmiştir. Toplamda 31 katılımcı $(\% 41,89)$ hiç veya az cevabını vermiştir. 7'şer katılımcı ise fazla ve çok fazla cevabını vermiştir. En çok verilen cevap orta olmasına rağmen sonraki cevapların ağırlığının hiç ve az olması, sürdürülebilir imalatların yeterli düzeyde yapılmadığını göstermektedir. Benzer durum az enerji tüketen ikame maddelerin kullanılıp kullanılmadığı sorusunda görülmüştür. Orta cevabını 25 katılımcı (33,78\%), 17 katılımcı $(22,97)$ az, 11 katılımcı $(14,86 \%)$ ise hiç cevabını vermiştir. Sektör temsilcilerinin yaklaşık dörtte üçü $(75,68 \%)$ kurumlarının çevre konusunda fazla veya çok fazla hassas olduklarını ifade etmişlerdir. Ürünlerde atık malzeme kullanılma sorusuna verilen cevaplar dengeli bir dağılım göstermiş olup tüm cavapların birbirine yakın olduğu söylenebilir. Sürdürülebilir ürün imal etmenin bireysel anlamda da önemli olduğu katılımcilar tarafindan ortaya konmuştur. Katılımcıların yarısı (37 katılımcı) bu soruya çok fazla, 20 katılımcı ise fazla cevabı vermiştir.

\subsection{AR-GE Çalışmalarında Sürdürülebilir Çözümler}

Tablo-4'te AR-GE çalışmalarında sürdürülebilir çcözümlerin ne derece yer aldığına yönelik sorulara verilen cevapların analiz yer almaktadır. Kurumunuzda çevre ve enerji bakımından daha 
verimli ürünler elde etme konusunda AR-GE çalışmaları yapılıp yapılmadığı ile ilgili soruya 12 'şer kişi hiç, orta ve fazla cevabını verirken, 22 kişi $(29,73 \%)$ az, 16 kişi $(29,73 \%)$ ise çok fazla cevabını vermiștir. Cevaplar belli bir aralıkta toplanmamakla beraber, hiç ve az cevabını verenlerin sayısının fazla ve çok fazla cevabını verenlerden fazla olduğu görülmektedir. AR-GE çalışmaları için yeterli bütçe ayrılıp ayrılmadığı ile ilgili soruya verilen cevaplarda ise hiç $(27,03 \%)$ ve az $(33,78 \%)$ cavapları ön plana çıkmaktadır. Bu konuda yeterli personel istihdam edilip edilmediği sorusuna yanıtta da benzer tablo gözlemlenmektedir. Hiç cevabının oranı $39,14 \%$ iken az cevabının oranı $24,32 \%$ olmuştur. Yeni çıkan ürünlerle ilgili eğitimler alınıp alınmadığı sorusunda ise hiç cevabından $(28,38 \%)$ sonra en çok oranı orta cevabı (27,03\%) almıştır. Üçüncü sırada az cevabı gelmektedir. Katılımcıların yarısına yakını (48,65\%) çevre dostu, sürdürülebilir ürünler imal etmek için fikir, proje vs. üretmediklerini ifade etmişlerdir.

\subsection{Sürdülebilirlik Konusunda Gelecekteki Beklentiler}

\section{Sonuç}

Nicel araştırma yöntemine dayalı bu çalışmada hazır beton firmalarının imalat stratejileri çevre bilinci ve sürdürülebilirlik açısından incelenmiştir. Çalışma 5 kategoride incelenmiş olup, bu kategorilerle ilgili sonuçlar şu şekilde özetlenmiştir:

- Çalışmaya katılan hazır beton firma yetkililerinin beton ve çimentonun çevreye ciddi şekilde zarar verdiklerini düşünmelerine rağmen bu malzemelerin iklim değişikliğindeki rolünü daha az ciddi buldukları, sürdürülebilir beton/yeşil beton, kendini yenileyen beton ve benzeri ürünler hakkındaki farkındalıklarının yeterli düzeyde olmadığı görülmüştür.

- Katılımciların her anlamda sürdürülebilir stratejileri yetersiz buldukları sonucu ortaya çıkmıştır. Özellikle sürdürülüebilir imalatlar konusunda teşvik ve yaptırımların çok yetersiz olduğu, sektördeki beton ve çimento firmaların yeterli düzeyde çevre bilinciyle hareket etmediği sonucu ortaya konmuştur.

- Katılımcilar, hem bireysel anlamda hem de kurumsal anlamda güçlü bir şekilde çevre konusunda hassas olduklarını ifade etmelerine rağmen, imalat süreçlerinde sürdürülebilir ürünleri yeteri kadar kullanmadıklarını, enerji tasarrufu sağlayıcı ikame malzamelerden de aynı şekilde yeterli düzeyde yararlanmadıklarını ifade etmişlerdir. Buna karşın atık ürün kullanma konusunda daha çok katılımcının pozitif cevap verdiği görülmektedir. Tüm bu bulgular, çevre hassasiyetinin mevcut imalat stratejilerine yeterli düzeyde yansımadığını ortaya koymaktadır.

- Hazır beton firması yetkilileri, kurumlarında sürdürülebilir üretim ile ilgili genel olarak AR-GE çalışmalarını belli bir düzeyde yaptıklarını ifade etmişler, buna karşın bu konuda yeterli personel ve bütçe ayrılmadığı, yeni çıkan ürünlerle ilgili yeterli düzeyde eğitimlerin düzenlenmediği sonucuna varılmıştır. Ek olarak, katılımcıların büyük bir çoğunun bu konuda herhangi bir fikir, proje vb. üretmediği görülmektedir.

- Sürdürülebilir ürünlerin gelecekteki yeri konusunda, katılımcıların çoğunlu)ğu betonun ömrünün
Tablo 5 'te sürdürülebilirlik konusunda gelecekteki beklentilere yönelik soruların analizleri yer almaktadır. Katılımcıların büyük çoğunluğu betonun ömrünün uzatılabileceği konusunda olumlu düşünmektedir. İlgili soruya verilen cevapların $32,43 \%$ 'ünü çok fazla, $29,73 \%$ 'ini ise fazla cevabı oluşturmaktadır. Betonun içine bakteri yerleştirme ve bu yolla betonun ömrünü uzatma fikrine ise katılımcılar daha çok çekimser veya olumsuz bakmaktadır. Bu konuda 25 katılıme1 (33,78\%) orta cevabını verirken, 14 katılımcı hiç, 19 katııımcı da az cevabını vermiştir. Benzer bir durum beton ve çimento kullanımının ileride azalacağına dair düşüncelerini irdeleyen soruda da yaşanmıştır. 24 katılımcı (32,43\%) orta cevabını verirken, 15 'er katılımcı ise hiç ve az cevabını vermiştir. Katılımcıların $43,24 \%$ çimentosuz betonun mümkün olmayacağını ve sürdürülebilir ve çevre dostu ürünlere ciddi bir talebin hiç olmadığını ifade etmiştir. İlgili sorulara verilen cevaplarda az cevabı ikinci sırada yer almıştır. ' 10 yıl içerisinde betonun pazardaki yerinin gerileceğini düşünüyor musunuz?' sorusunda ise yine çekimser ya da olumsuz bakış açılarının hakim olduğu söylenebilir. Bu soruya 25 katılımcı $(33,78 \%)$ orta cevabını verirken, 20 katılımc $(27,03 \%)$ az cevabını vermiştir.

uzatılabileceğini fakat çimentosuz beton, bakteri ihtiva eden beton kullanımı gibi fikirlerin çok yaygın olmayacağı görüşündedir. Ayrıca sürdülebilir ürünlere yönelik talebin azlı̆g 1 ve ileride betona olan talebin azalmayacağı fikri de bu görüşü destekler niteliktedir.

Tüm bu kategori sonuçları doğrultusunda, beton firmalarının sürdürülebilirlik konusunda istenen seviyede olmadıkları görülmektedir. Bu durumu iyileştirmek için firmalara ilgili oda, birlik ve kamu kurumlarınca eğitimlerin verilmesi farkındalığı arttıracaktır. Ayrıca uygulanacak teşvik ve yaptırımlar bu tür ürünlerin yaygınlaştııılmasını daha da mümkün kılacaktır. Bu sayede AR-GE çalışmaları da gelişebilecektir. Özellikle bu konuda teşvikler önemli rol oynayacaktır. Teşvik ve yaptırımlar sadece hazır beton firmaları ile sınırlı kalmamalı, bu konuda talebi arttıracak çözümler gerekecektir. Yapı sektöründe yer alan tüm paydaşların bu konuya eğilmeleri sağlanmalıdır. Ozelikle yeni nesil sürdürülebilir beton çalışmaları için kamu-özel sektörüniversite işbirliklerinin geliştirilmesi önem arz etmektedir.

\section{Kaynakça}

Altınıșık, D. D. (2014). Sürdürülebilirlik Kavramı Bağlamında Geri Kazanılmış Agregalı Beton (Doctoral dissertation, Fen Bilimleri Enstitüsü).

Arıoğlu, N., Hatipoğlu, D. D., Arıŏlu Salmona, M. O., \& Arıoğlu, E. (2004). Sürdürülebilirlik Kavramı Anlayıșında Beton Endüstrisinin İrdelenmesi', 11. Beton Prefabrikasyon Seтроzуити, İzmir.

Assi, L., Carter, K., Deaver, E. E., Anay, R., \& Ziehl, P. (2018). Sustainable concrete: Building a greener future. Journal of cleaner production, 198, 1641-1651.

Berndt, M. L. (2009). Properties of sustainable concrete containing fly ash, slag and recycled concrete aggregate. Construction and building materials, 23(7), 26062613.

BOSTANCI, S. C. (2019). Engineering Properties and Sustainability Assessment of Recycled Glass Sand Concrete. Avrupa Bilim ve Teknoloji Dergisi, (17), 117-130.

BOZKURT, N., \& YAZICIOĞLU, S.(2010). SÜRDÜRÜLEBILIR TAȘIYICI HAFIF BETON 
TASARIMI VE MEKANIK ÖZELLIKLERININ

ARAȘTIRILMASI SUSTAINABLE STRUCTURAL LIGHTWEIGHT CONCRETE DESIGN AND THE INVESTIGATION OF THE MECHANICAL PROPERTIES.

Coşkun, İ., Tandırcı, E., \& Kurt, S. (2017). Geri Dönüşüm Suyu İkamesinin Beton Üretimine Etkileri. Hazır Beton Dergisi, 144, 73-80.

Demirel, C., \& Şimşek, O. (2015). Erken yaşdaki atık betonların geri dönüşüm agregası olarak beton üretiminde kullanılabilirliği ve sürdürülebilirlik açısından incelenmesi. Düzce Üniversitesi Bilim ve Teknoloji Dergisi, 3(1), 226-235.

Doğan, H., \& YILANKIRKAN, N. (2015). Türkiye'nin enerji verimliliği potansiyeli ve projeksiyonu. Gazi Üniversitesi Fen Bilimleri Dergisi Part C: Tasarm ve Teknoloji, 3(1), 375-384.

Dosho, Y. (2007). Development of a sustainable concrete waste recycling system. Journal of Advanced Concrete Technology, 5(1), 27-42.

Goksu, C., IlyasSaribas, Y. A., \& Ilki, A. (2018). GERI DÖNÜŞTÜRÜLMÜŞ AGREGA İLE ELDE EDILEN BETONUN MEKANIK ÖZELLIKLLRİ.

GÜNER, C., GÖKŞEN, F., \& KOÇHAN, A. (2017). Sürdürülebilir Kalkınma Modeli için Çevre Duyarlı Yapılarda Malzeme Seçiminin İncelenmesi. Akademia Disiplinlerarası Bilimsel Araştırmalar Dergisi, 3(2), 1-14.

Jonkers, H. M., Thijssen, A., Muyzer, G., Copuroglu, O., \& Schlangen, E. (2010). Application of bacteria as self-healing agent for the development of sustainable concrete. Ecological engineering, 36(2), 230-235.

Monteiro, P. J., Miller, S. A., \& Horvath, A. (2017). Towards sustainable concrete. Nature materials, 16(7), 698-699.

Naik, T. R. (2008). Sustainability of concrete construction. Practice Periodical on Structural Design and Construction, 13(2), 98-103.

Orhon, A. V. (2012, September). Tasarımdan yapıma, sürdürülebilir beton yaklaşımları. In Proceedings of 2 nd project and construction management congress, Izmir Institute of Technology, Izmir (pp. 13-16).

Özcan, U., \& Güngör, S. (2019). Sürdürülebilir Bir Yöntem/Betonda Puzolan Kullanımı. Avrupa Bilim ve Teknoloji Dergisi, (15), 176-182.

Özel, S. E. V. D. A. (2018). Türkiye'de Deponi Alanlarının Sürdürülebilir Çevre Koruma ve Çevresel Etkilerine İlişkin Bir Değerlendirme. Avrupa Bilim ve Teknoloji Dergisi, (13), 31-38.

SANCAK, E., \& ŞAMANDAR. (2015). A. SÜRDÜRÜLEBILLIRLIK BAKIMINDAN KENDILIIGĞINDEN YERLEȘEN BETON KULLANIMININ ROLÜ.

Toker, M. (2013). Enerji Tüketimi Ve Emisyonların Düşürülmesi Amaciyla Çimento Üretiminde Mineral Katklların Kullanıminin Optimizasyonu (Doctoral dissertation, Fen Bilimleri Enstitüsü).

Yılmaz, Y., Işıı, A., Kılınç, C., \& Eren, E. (2013). Beton Endüstrisinde Sürdürülebilir Üretim. 